\title{
SIMPLE CRUD BUKU TAMU PERPUSTAKAAN BERBASIS PHP DAN MYSQL :LANGKAH-LANGKAH PEMBUATAN
}

\author{
Rima Safitri \\ Pustakawan Universitas Negeri Jakarta \\ zafirnirwana@gmail.com
}

\begin{abstract}
ABSTRAK
Buku tamu merupakan suatu hal yang lazim ada di perpustakaan. Format buku tamu ada yang berbentuk cetak maupun elektronik. Format elektronik buku tamu dirancang dari bahasa pemrograman komputer. Banyak aplikasi perpustakaan yang ada sudah dilengkapi dengan modul buku tamu. Simple CRUD buku tamu adalah proses pembuatan sebuah aplikasi sederhana menggunakan bahasa pemrograman PHP dan MySQL. Program PHP dan MySQL tersebut biasanya sudah dibundling dalam satu paket bernama XAMPP. Paket XAMPP merupakan perangkat lunak bebas, yang mendukung banyak sistem operasi. Langkah-langkah pembuatan dimulai dari instalasi paket XAMPP, kemudian perancangan database MySQL, dan pembuatan file-file eksekusi yang disimpan dalam file ekstensi PHP, sehingga menghasilkan sebuah aplikasi buku tamu.
\end{abstract}

Kata Kunci: Buku tamu, $P H P, M y S Q L$

\section{PENDAHULUAN}

Seiring dengan majunya
teknologi informasi, penerapan
teknologi di berbagai bidang sudah
menjadi suatu hal yang tidak asing. Di
era generasi digital, kebutuhan
seseorang ditransformasi menjadi suatu
aplikasi baru yang memberikan
berbagai kemudahan dalam beragam
aktivitas. Peran teknologi informasi ini
pun sangat berpengaruh dalam bidang
perpustakaan, terutama
perpustakaan barena
penyediaan informasi
pemakainya. kepada

Buku tamu adalah suatu hal yang lazim ada di perpustakaan. Ada dua bentuk buku tamu, yakni bentuk cetak berupa lembar lepas atau buku, dan non cetak atau elektronik. Buku tamu perpustakaan disediakan untuk mencatat kehadiran pengunjung ke perpustakaan, biasanya buku tamu berisi catatan identitas pengunjung. Data buku tamu tersebut kemudian dikumpulkan untuk dijadikan laporan berupa statistik pengunjung perpustakaan dalam kurun waktu tertentu.

Pada saat ini sudah banyak aplikasi buku tamu elektronik baik yang gratis maupun berbayar. Software perpustakaan yang lengkap biasanya 
sudah menyediakan modul untuk buku tamu tersebut. Ada banyak variasi bahasapemrograman dalam membuat software perpustakaan seperti Visual Basic, Foxpro, SQL, PHP, dan lain-lain. Namun saat ini yang paling banyak dipakai adalah program PHP dan MySQL.

Program PHP dan MySQL yang ada sekarang sudah dibundling dalam satu paket program bernama XAMPP. XAMPP merupakan paket PHP berbasis Open Source. XAMPP mengkombinasi beberapa paket perangkat lunak berbeda ke dalam satu paket. Paket yang disediakan antara lain adalah Apache, MySQL, PHP, FilZilla FTP Server, phpMyAdmin, dan lain-lain.

Simple CRUD buku tamu adalah aplikasi sederhana tentang pembuatan buku tamu perpustakaan menggunakan bahasa pemrograman PHP dan MySQL. CRUD merupakan kepanjangan dari inisial huruf awal Create, Read, Update, dan Delete. Operasi CRUD adalah manipulasi data dasar untuk database. Operasi ini dibuat menggunakan program PHP, sedangkan untuk database memakai program MySQL. Langkah-langkah pembuatan buku tamu perpustakaan dibuat secara sistematis dan sederhana sehingga dapat

diterapkan dengan mudah.

\section{DEFINISI}

Pengertian buku tamu menurut Kamus besar Bahasa Indonesia (2015), adalah buku yang berisi nama tamu yang hadir di pertemuan (rapat, resepsi, kantor, dan sebagainya). Seperti halnya juga perpustakaan memiliki buku tamu atau buku pengunjung sebagai bukti adanya aktivitas layanan di lembaga tersebut. Buku tamu dibuat untuk mencatat kehadiran pengunjung perpustakaan setiap hari. Isi buku tamu ada bermacam-macam, mulai dari yang sederhana hingga kompleks.Isiannya mencakup nama, alamat, jabatan, status, alamat email, keperluan khusus, dan lain-lain.

Pengertian XAMPP menurut wikipedia (2017), adalah perangkat lunak bebas, yang mendukung banyak sistem operasi, dan merupakan kompilasi dari beberapa program. Fungsi XAMPP adalah sebagai server yang berdiri sendiri (localhost), terdiri atas program Apache HTTP Server, MySQL database, dan penerjemah bahasa yang ditulis dengan bahasa pemrograman PHP dan Perl. Nama XAMPP merupakan singkatan dari $\mathrm{X}$ (empat sistem operasi apapun), Apache, 
MySQL, PHP dan Perl. Program ini tersedia dalam GNU General Public License dan bebas, merupakan web server yang mudah digunakan yang dapat melayani tampilan halaman web yang dinamis. XAMPP dikembangkan dari sebuah tim proyek bernama Apache Friends, yang terdiri dari Tim Inti (Core Team), Tim Pengembang (Development Team) \& Tim Dukungan (Support Team)

PHP, kependekan dari Personal Home Page (Situs personal), menurut wikipedia adalah bahasa skrip yang dapat ditanamkan atau disisipkan ke dalam HTML. PHP banyak dipakai untuk memprogram situs web dinamis. PHP dapat digunakan untuk membangun sebuah CMS. PHP dapat digunakan di berbagai mesin (Linux, Unix, Macintosh, Windows) dan dapat dijalankan secara runtime melalui console serta juga dapat menjalankan perintah-perintah sistem.

Menurut kamus komputer, PHP adalah bahasa pemrograman untuk dijalankan melalui halaman web, umumnya digunakan untuk mengolah informasi di internet. Sedangkan pengertian lain PHP adalah singkatan dari PHP Hypertext Preprocessor yaitu bahasa pemrograman web server-side yang bersifat open source atau gratis. PHP merupakan script yang menyatu dengan HTML dan berada pada server (server side HTML embedded scripting). (Rulianto Kurniawan, 2010)

Menurut wikipedia (2018), MySQL adalah sebuah implementasi dari sistem manajemen basis data relasional (RDBMS) yang didistribusikan secara gratis di bawah lisensi GPL (General Public License). Setiap pengguna dapat secara bebas menggunakan MySQL, namun dengan batasan perangkat lunak tersebut tidak boleh dijadikan produk turunan yang bersifat komersial. MySQL sebenarnya merupakan turunan salah satu konsep utama dalam basisdata yang telah ada sebelumnya; SQL (Structured Query Language). SQL adalah sebuah konsep pengoperasian basisdata, terutama untuk pemilihan atau seleksi dan pemasukan data, yang memungkinkan pengoperasian data dikerjakan dengan mudah secara otomatis.

MySQL menurut Van der Lans, ..."MySQL is a relational database server that supports the well-known SQL (Structured Query Language) database language”. Artinya MySQL adalah server basis data relasional yang mendukung bahasa basis data SQL 
(Structured Query Language) yang terkenal. (Rick F. Van der Lans, 2007)

MySQL adalah salah satu jenis database server yang terkenal. MySQL merupakan jenis RDBMS (Relational Database Management System) dimana istilah-istilah seperti table, baris, dan kolom digunakan. (Rulianto Kurniawan, 2010)

\section{LANGKAH-LANGKAH PEMBUATAN APLIKASI BUKU TAMU}

Ada beberapa langkah yang dilakukan untuk membuat aplikasi buku tamu berbasis PHP dan MySQL. Hal pertama dilakukan adalah menyiapkan program PHP dan MySQL. Program PHP dan MySQL dari paket bundling bernama XAMPP dapat diperoleh melalui website https://www.apachefriends.org/.

Instalasi paket ini disesuaikan dengan sistem operasi komputer yang digunakan, seperti windows, mac, atau linux.(http://www.sistemphp.com/ : 2015)

Langkah-langkah pembuatan aplikasi buku tamu adalah sebagai berikut:

a) Instalasi paket XAMPP
Instal file XAMPP pada drive

direktori yang diinginkan, ikuti

langkah-langkah

penginstalannya sampai selesai.

b) Membuat folder TAMU di drive direktori yang telah ditetapkan, misalnya driveC: Ixamppไhtdocs atau drive D: Ixampp\htdocs

Semua file yang berkaitan dengan aplikasi buku tamu disimpan dalam folder tersebut.

c) Membuat database Buku Tamu Untuk membuat database pada program MySQL, buka file XAMPP Contol Panel,

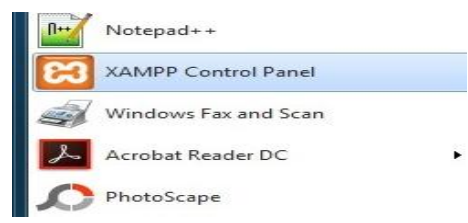

Gambar 1. XAMPP Control Panel Lalu Klik tombol Start pada Module Apache dan MySQL

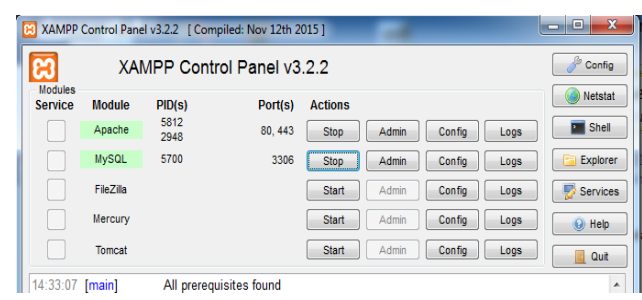

Gambar 2. Start module Apache dan MySQL

Untuk membuat database Buku Tamu, buka jendela browser Mozilla atau Google Crome,

Program Studi Perpustakaan dan Sains Informasi Universitas Wijaya Kusuma Surabaya 


\section{Ketik}

http://localhost/phpmyadmin/ ,

lalu tekan enter

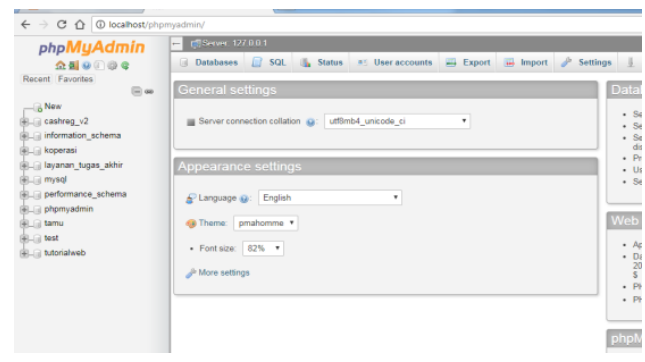

Gambar 3. Tampilan phpMyAdmin

Klik New, untuk membuat database baru, beri nama "tamu”, lalu klik tombol Create

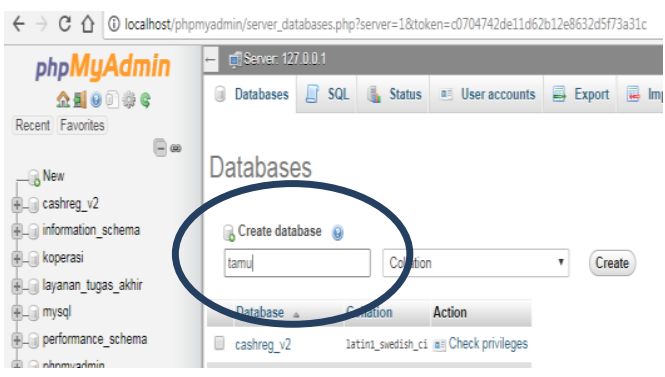

Gambar 4. Membuat nama database

Selanjutnya membuat TABEL baru dengan nama 'bukutamu'

dengan script dibawah ini :

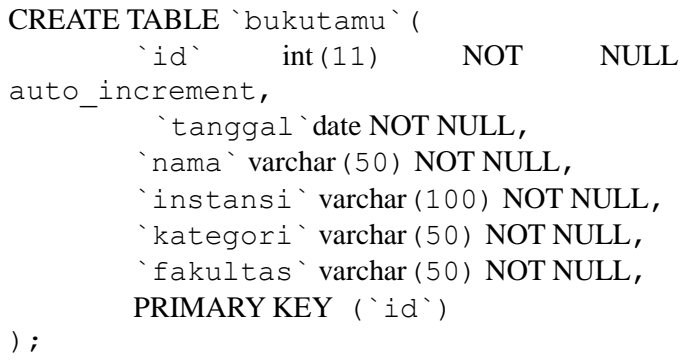

'id` int (11) NOT NULL 
- daftar-tamu.php

- about.php

Semua file tersebut disimpan pada folder tamu,contoh

D: Ixamppไhtdocsltamu. Setiap file ekstensi php berisi skrip bahasa pemrograman yang ditulis dengan menggunakan program notepad. Program notepad yang dianjurkan adalah notepad++.

Adapun rincian skrip bahasa pemrograman tersebut adalah sebagai berikut :

1) File connect.php

$<$ ?php

\$connect

$=$

mysql_connect("localhost","root","

")

or die(mysql_error());

mysql_select_db("tamu",\$connect); ?>

2) File index.php

$<\mathrm{html}>$

$<$ head>

$<$ title>Selamat Datang </title>

<body bgcolor="lime">

$<$ font face="tahoma" $><$ font

color="black" $><$ font

size $=" 7 ">\langle$ hr $><$ center $>$

$<$ b $>$ Selamat Datang di UPT

Perpustakaan $<$ br $>$ Universitas
Negeri

Jakarta $<$ br $></$ font $><$ hr $></$ font $>$

$<\mathrm{br} />$

<img src="uptperpus.jpg" width="350"

height="250" $>\langle$ br $>$

$</$ head $>$

$<$ body $>$

$<$ table width="430" border="0"

align="center">

$<\operatorname{tr}>$

$<$ td width="68"><a href="index.php"> [

Home ] $</$ td $>$

$</$ td $>$

$<$ td width="112" ><a href="2.php" $>$ [Isi

Buku tamu] $</$ a $\rangle\langle/$ td $>$

$<$ td width="112" $><\mathrm{a} \quad$ href="daftartamu.php" $>$ [Daftar Tamu] $</$ a $></$ td $>$

$<$ td width $=" 112 "><\mathrm{a}$

href="about.php" $>$ [About $]</ a></$ td $>$

$<\mathrm{hr}>$

$<\mathrm{i}><$ font

color="black"

size $=" 5 ">$ Selamat datang Pengunjung

Perpustakaan <br>

Anda bisa mendaftarkan diri anda menjadi tamu kami <br>

klik link "isi buku tamu" untuk menjadi tamu

kami $<$ br $>$ Terimakasih $</$ font $><$ hr $><$ br $>$

$</$ tr $></$ table $></$ form $></$ body $></$ html $>$

Program Studi Perpustakaan dan Sains Informasi Universitas Wijaya Kusuma Surabaya 
3) File2.php $<$ html $><$ head $><$ title $>$ Buk

u $\quad$ Tamu $\quad</$ title $><$ body
bgcolor="white" $><$ center $>$

$$
\begin{aligned}
& \text { <img } \quad \text { src="uptperpus.jpg" } \\
& \text { width="150" } \\
& \text { height="100" ></center }><\text { br } \\
& > \\
& </ \text { head }> \\
& <\text { body }> \\
& <\text { div }>
\end{aligned}
$$$$
<\text { form action = }
$$$$
\text { "2_proses.php" }
$$$$
\text { method="POST"> }
$$$$
\text { <table> }
$$$$
<\text { h1 }><\text { b }>\text { DAFTAR }
$$$$
\text { PENGUNJUNG }</ \text { b }></ \text { h1 }>
$$$$
\langle\mathrm{p}\rangle\langle\mathrm{b}\rangle \text { Silahkan isi daftar }
$$$$
\text { pengunjung di bawah }
$$$$
\text { ini }</ \text { b }\rangle\langle/ \text { p }>
$$$$
<\text { form action="" }
$$$$
\text { method="post"> }
$$$$
<\text { table cellpadding="40" }
$$$$
\text { cellspacing="50"> }
$$$$
\langle\mathrm{p}\rangle\langle\mathrm{b}\rangle \text { Nama Lengkap }
$$$$
:</ \text { b }\rangle\langle\text { br }\rangle<\text { input type="text" }
$$$$
\text { name }=\text { "Nama" }
$$$$
\text { size }=" 50 ">\langle/ p>
$$$$
\langle\mathrm{p}\rangle\langle\mathrm{b}>\text { Instansi }
$$$$
\text { Asal }
$$$$
:</ \text { b }\rangle\langle\text { br }><\text { input type="text" }
$$$$
\text { name="Instansi" }
$$$$
\text { size }=" 80 ">\langle/ \text { p }\rangle
$$

$$
\begin{aligned}
& \langle\mathrm{p}\rangle\langle\mathrm{b}>\text { Kategori } \\
& :\langle/ \mathrm{b}\rangle\langle\text { br }>\langle\text { Select } \\
& \text { name="Kategori" }> \\
& \quad<\text { option value="" }>\text { Pilih }
\end{aligned}
$$

Kategori</option>

<option

value $=$ "Siswa" $>$ Siswa $</$ opti

on $><$ option

value $=$ "Mahasiswa" $>$ Mahasi

swa</option>

<option

value $=$ "Guru" $>$ Guru</option

$>$

<option

value $=$ "Dosen" $>$ Dosen $</$ opti

on>

<option

value="Umum" $>$ Umum $</$ op

tion $></$ Select $></$ p $>$

$$
<\mathrm{P}\rangle</ \mathrm{P}\rangle
$$$$
\langle\mathrm{P}\rangle\langle/ \mathrm{P}\rangle
$$$$
\langle\mathrm{P}\rangle\langle/ \mathrm{P}\rangle
$$

$\langle\mathrm{p}\rangle\langle\mathrm{b}\rangle$ Untuk

Mahasiswa UNJ, Silahkan

PILIH daftar FAKULTAS di

bawah ini $</$ b $></$ p $>$

$\langle\mathrm{p}\rangle\langle\mathrm{b}\rangle$ Fakultas

$:</ \mathrm{b}\rangle\langle$ br $\rangle\langle$ SELECT

name="Fakultas" rows="5"

cols $=" 10 ">$

<option value $="$ ">Pilih

Fakultas</option> 


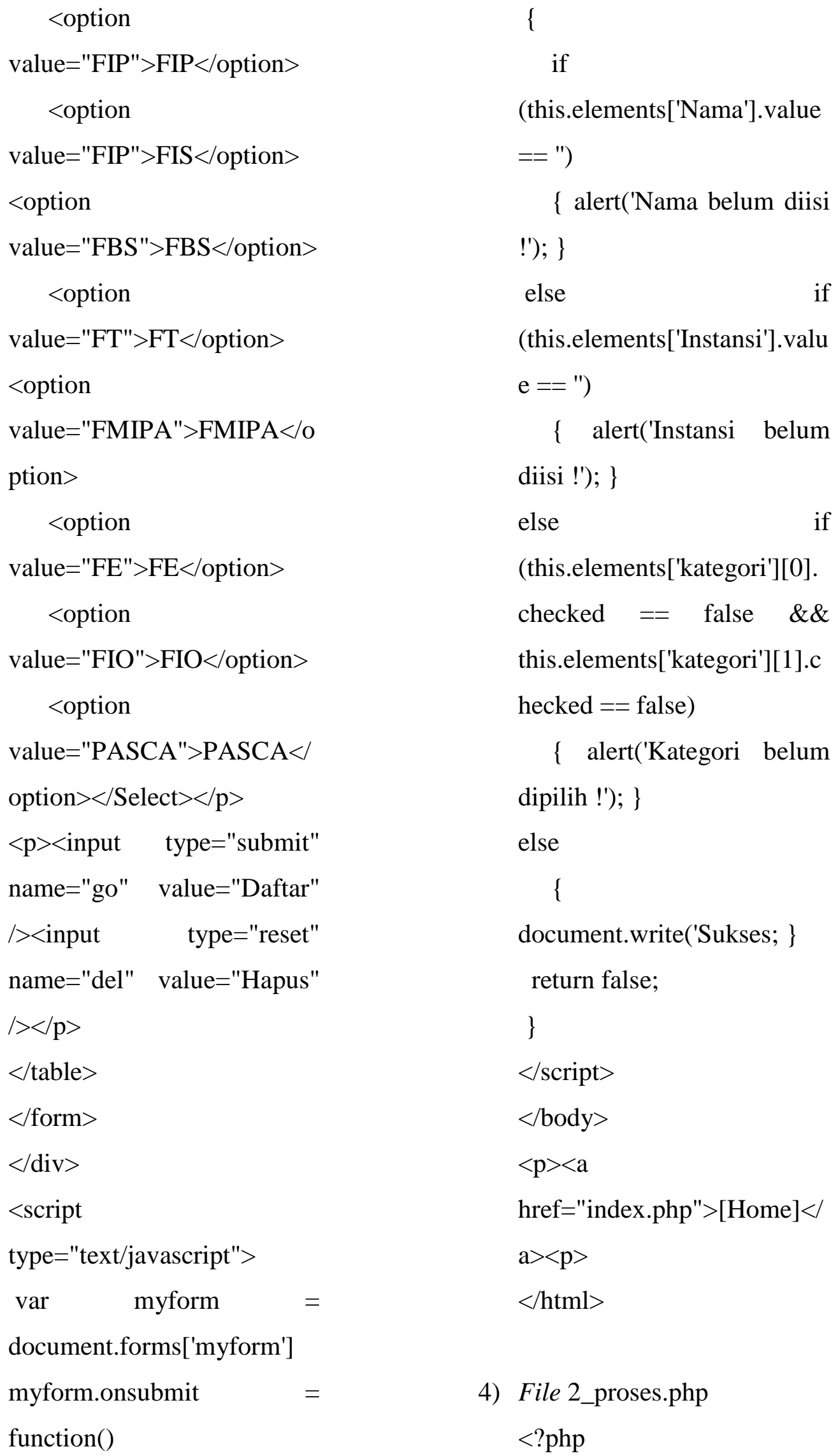

4) File 2_proses.php $<$ ?php 


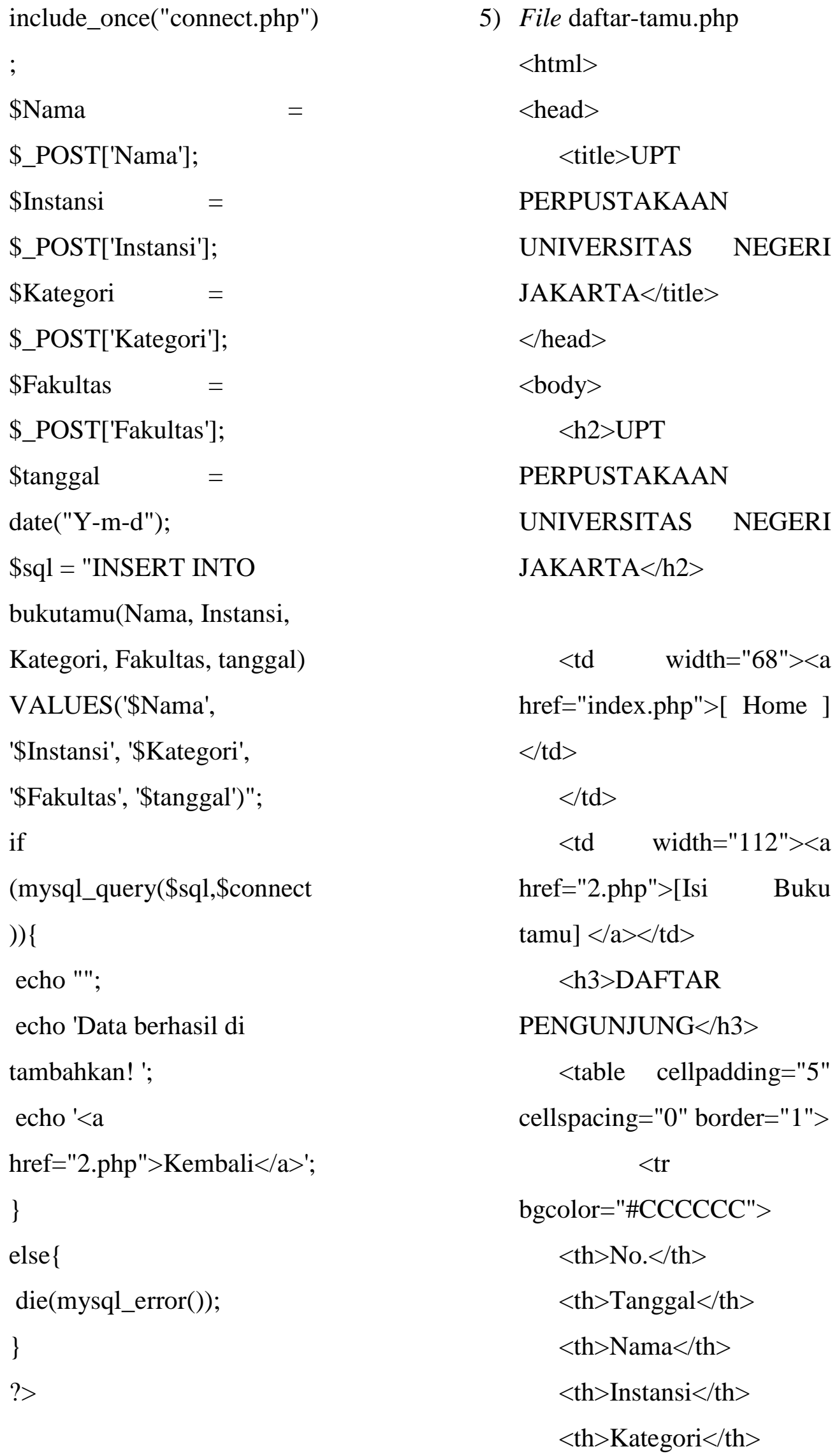

5) File daftar-tamu.php

$<\mathrm{html}>$

$<$ head $>$

$<$ title>UPT

PERPUSTAKAAN

UNIVERSITAS NEGERI

JAKARTA</title>

$</$ head $>$

<body>

$<$ h2>UPT

PERPUSTAKAAN

UNIVERSITAS NEGERI

JAKARTA $</ \mathrm{h} 2>$ 
$<$ th $>$ Fakultas $</$ th $>$

$</ \operatorname{tr}\rangle$

$$
<\text { ?php }
$$

//iclude

file

koneksi ke database

$$
\text { include('connect.php'); }
$$

//query ke database dg

SELECT table bukutamu

diurutkan berdasarkan

Nomor

\$query=

mysql_query("SELECT *

FROM bukutamu ORDER

BY id DESC") or

die(mysql_error());

//cek, apakakah hasil query di atas mendapatkan hasil atau tidak (data kosong atau tidak)

if(mysql_num_rows(\$qu

ery) $==0)\{$

//ini

artinya jika data hasil query

di atas kosong

//jika data kosong, maka akan menampilkan row kosong

\author{
echo' $<\mathrm{tr}\rangle\langle\mathrm{td}$ \\ colspan="6"> Tidak ada \\ data $\mid</$ td $\rangle\langle/$ tr $\rangle$;
}

\}else\{ //else ini artinya jika data hasil query ada (data diu database tidak kosong)

//jika data tidak kosong, maka akan melakukan perulangan while

$$
\begin{array}{lll}
\text { \$no } & = & 1 ; \\
/ / \text { membuat } & \text { variabel } & \text { \$no }
\end{array}
$$

untuk membuat nomor urut

$$
\text { while(\$data }
$$

mysql_fetch_assoc(\$query))

\{ //perulangan while dg membuat variabel \$data yang akan mengambil data di database//menampilkan row dengan data di database

$$
\begin{aligned}
& \text { echo '<tr>'; } \\
& \text { echo '<td }>\text { '.\$no.' }</ \mathrm{td}>\text { '; } \\
& \text { //menampilkan nomor }
\end{aligned}
$$
urut

echo '<td >'date('Y-md').'</td >'; //menampilkan data tanggal daftar dari database 


\begin{tabular}{|c|c|}
\hline echo & $<$ link $\quad$ REL="SHORTCUT \\
\hline '<td>'.\$data['nama'].'</td >'; & ICON" \\
\hline //menampilkan & HREF="https://fbcdn- \\
\hline nama dari database & profile- \\
\hline echo & a.akamaihd.net/hprofile-ak- \\
\hline '<td>'.\$data['instansi'].'</td>' & $\mathrm{prn} 1 / \mathrm{c} 36.36 .445 .445 / \mathrm{s} 200 \mathrm{x} 2$ \\
\hline ; //menampilkan data & 00/943592_5913562708882 \\
\hline instansi dari database & 17_1056283617_n.jpg"> \\
\hline echo & $<$ title $>$ Tentang Kami $</$ title $>$ \\
\hline '<td>'.\$data['kategori'].'</td $>$ & $<$ body style= " background- \\
\hline '; //menampilkan data & image:phplogos.jpg" $></$ body \\
\hline kategori dari database & $>$ \\
\hline echo & $<$ center $\rangle\langle$ h 1$\rangle<$ font \\
\hline '<td>'.\$data['fakultas'].'</td >' & color="blue" $><$ font \\
\hline ; //menampilkan data & size="7">Tentang \\
\hline fakultas dari database & Kami $</$ font $></$ font $></$ h $1><$ b \\
\hline echo '</tr>'; & $\mathrm{r}>$ \\
\hline & <img $\quad$ src="phplogos.jpg" \\
\hline \$no++;//menambah & width="400" \\
\hline jumlah nomor urut setiap & height="200" $><$ br $>$ \\
\hline row & $<\mathrm{hr}>$ \\
\hline$\}$ & color="blue" \\
\hline$\}$ & size="5">Aplikasi \\
\hline$?>$ & tamu ini dibuat pada bulan \\
\hline$</$ table $>$ & agustus $2017<$ br> \\
\hline$</$ body $>$ & Aplikasi berbasis PHP dan \\
\hline$</ \mathrm{html}>$ & MySQL ini bersifat open \\
\hline File about.php & source $<$ br $>$ \\
\hline$<\mathrm{html}>$ & Terima kasih atas kunjungan \\
\hline$<$ Head $>$ & anda $\langle$ br $>$ \\
\hline <body bgcolor="white"> & $</$ font $>$ \\
\hline & $\langle\mathrm{hr}\rangle\langle\mathrm{br}\rangle$ \\
\hline
\end{tabular}


$<$ font color="blue"
size="5" $>$ Jika anda berminat
menjadi tamu kami, anda
bisa mengisi formulir di
bawah ini $</$ font $></$ i $><$ br $>$

$<\mathrm{A} \quad \mathrm{HREF}=$ "index.php" $>$ Home $\langle/$ A $\rangle\langle$ br $\rangle$

$<\mathrm{A} \quad \mathrm{HREF}=$ "2.php" $>$

Menjadi tamu $</ \mathrm{A}>\langle$ br $>$

Setelah semua file PHP disimpan dalam folder tamu, kemudian hal-hal yang perlu dilakukan untuk menjalankan aplikasi buku tamu adalah sebagai berikut:

- Membuka program XAMPP Control Panel, dengan cara mengklik tombol start, lalu pilih program XAMPP Control Panel. (lihat gambar 1)

- Mengaktifkan tombol start pada modul APACHE dan MySQL (gambar 2)

- Membuka jendela browser, lalu mengetikkan alamat "localhost/tamu", setelah itu tekan tombol enter. Bentuk tampilannya seperti gambar dibawah ini.

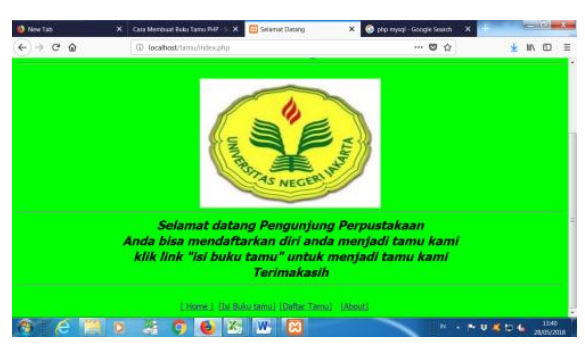

Gambar 7. Tampilan halaman muka aplikasi buku tamu File eksekusi yang tertera di alamat browser tersebut adalah file index.php. Pada halaman muka terdapat pilihan menu seperti [Home], [isi buku Tamu], [Daftar Tamu], dan [About]. Bila menu [Home] diklik maka halaman muka akan ditampilkan (gambar 7).

- Untuk mengisi buku tamu, klik menu [isi buku Tamu] yang merupakan eksekusi dari file 2.php. Tampilannya adalah seperti berikut

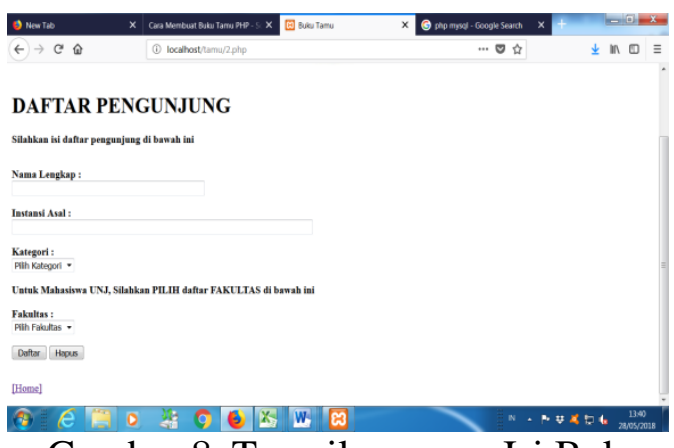

Gambar 8. Tampilan menu Isi Buku

Tamu 
- Pengunjung yang telah mengisi buku tamu datanya disimpan dalam database tamu. Proses penyimpanan data tersebut dieksekusi menggunakan file 2_proses.php . Tampilan daftar pengunjung dapat dilihat dari menu [Daftar Tamu] yang merupakan eksekusi dari file daftar-tamu.php. Bentuk tampilannya seperti di bawah ini.

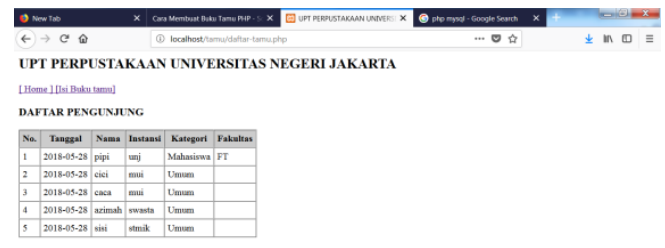

Gambar 9. Tampilan menu Daftar Tamu

- Menu pelengkap yang ditampilkan dalam aplikasi buku tamu adalah menu [About]. Menu ini berisi sekilas info tentang aplikasi. Bentuk tampilannya sebagai berikut.

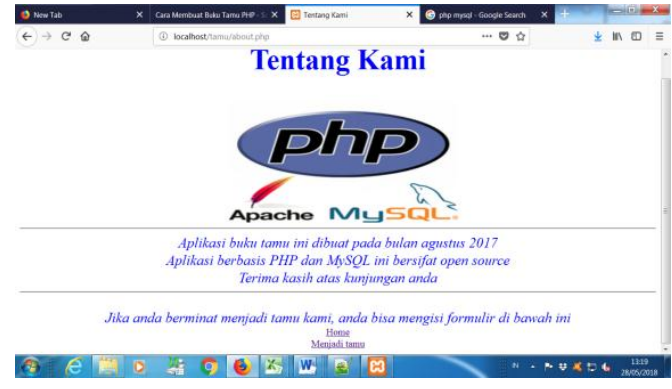

Gambar 10. Tampilan menu About

\section{PENUTUP}

Banyak bahasa pemrograman yang dipakai dalam membuat sebuah aplikasi, namun yang paling populer pada saat ini adalah bahasa pemrograman PHP dan MySQL. Populer digunakan karena bersifat open source sehingga setiap orang dapat merancang bahasa skrip untuk menghasilkan sebuah program atau aplikasi baru.

Aplikasi buku tamu sederhana yang dirancang ini menggunakan bahasa simple CRUD (Create, Read, Update, dan Delete) yang merupakan tahap awal dari pembelajaran pemrograman PHP. Artinya menciptakan (create) sebuah database tamu yang dapat dilihat (read), dan kemudian dapat diperbaharui (update) ataupun dihapus (delete). Pengembangan aplikasi ini dapat dilakukan untuk menciptakan sebuah aplikasi yang lebih variatif dan sesuai dengan kebutuhan konsumen yang

Program Studi Perpustakaan dan Sains Informasi Universitas Wijaya Kusuma Surabaya 
memakainya.

\section{Daftar Pustaka}

Cara Membuat Buku Tamu PHP. (2015). Retrieved August 25, 2017, from SISTEMPHP.COM : http://www.sistemphp.com/caramembuat-buku-tamu-php/

Departemen Pendidikan Nasional. (2013). Kamus besar bahasa Indonesia pusat bahasa. Jakarta : Gramedia Pustaka Utama

Kurniawan, Rulianto. (2010). PHP dan MySQL untuk orang awam. Palembang : Maxikom

Lans, Rick F.Van der. (2007). SQL for MySQL developers : a comprehensive tutorial and reference. Boston : Pearson Education

Maulana, Boby. (2015). Cara membuat aplikasi buku tamu menggunakan PHP dan database localhost. Retrieved August 23, 2017 : $\quad$ http://ilmunation.blogspot.co.id/2015/07/ca ra-membuat-aplikasi-bukutamu_24.html

MySQL (2018). Retrieved May 25, 2018, from Wikipedia bahasa Indonesia, ensiklopedia bebas

https://id.wikipedia.org/wiki/MySQL

PHP. Retrieved May 25, 2018, from Wikipedia bahasa Indonesia, ensiklopedia bebas : https://id.wikipedia.org/wiki/PH $\mathrm{P}$

XAMPP. (2017). Retrieved May 25, 2018, from Wikipedia bahasa Indonesia, ensiklopedia bebas : https://id.wikipedia.org/wiki/XA MPP 